\title{
Entrevista
}

\section{La ética en \\ esta sociedad \\ transformada}

DOI: 10.29236/sistemas.n153a3

La influencia ejercida por la tecnología exige una seria reflexión a partir de la ética, enfatiza el Padre Vicente Durán Casas en esta entrevista.

\section{Manuel Dávila Sguerra}

La autorizada voz del Padre Vicente Durán Casas tiene un amplio recorrido profesional como licenciado en filosofía y teología de la Universidad Javeriana y doctor en filosofía por la Hochshule für Philosophie de Munich, con una tesis sobre la ética de Kant. Profesor titular de filosofía de la $U \mathrm{~J}$, fue decano de la facultad de filosofía y vicerrector académico de la misma universidad. Profesor de filosofía moderna, filosofía política y filosofía de la religión. Ha publicado diversos artículos y libros sobre filosofía.
Manuel Dávila: La ética es un concepto universal de la relación entre las personas. En este mundo transformado por las tecnologías, me gustaría conocer su opinión, como filósofo, si el análisis ético en el mundo digital transformará algunos principios de la ética.

Padre Vicente Durán: En mi opinión, la ética siempre ha estado afectada y transformada por lo que pasa en el mundo. Basta citar algunos ejemplos: en los negocios no surgió sino cuando ese ambiente se convirtió en un tema cotidiano. 


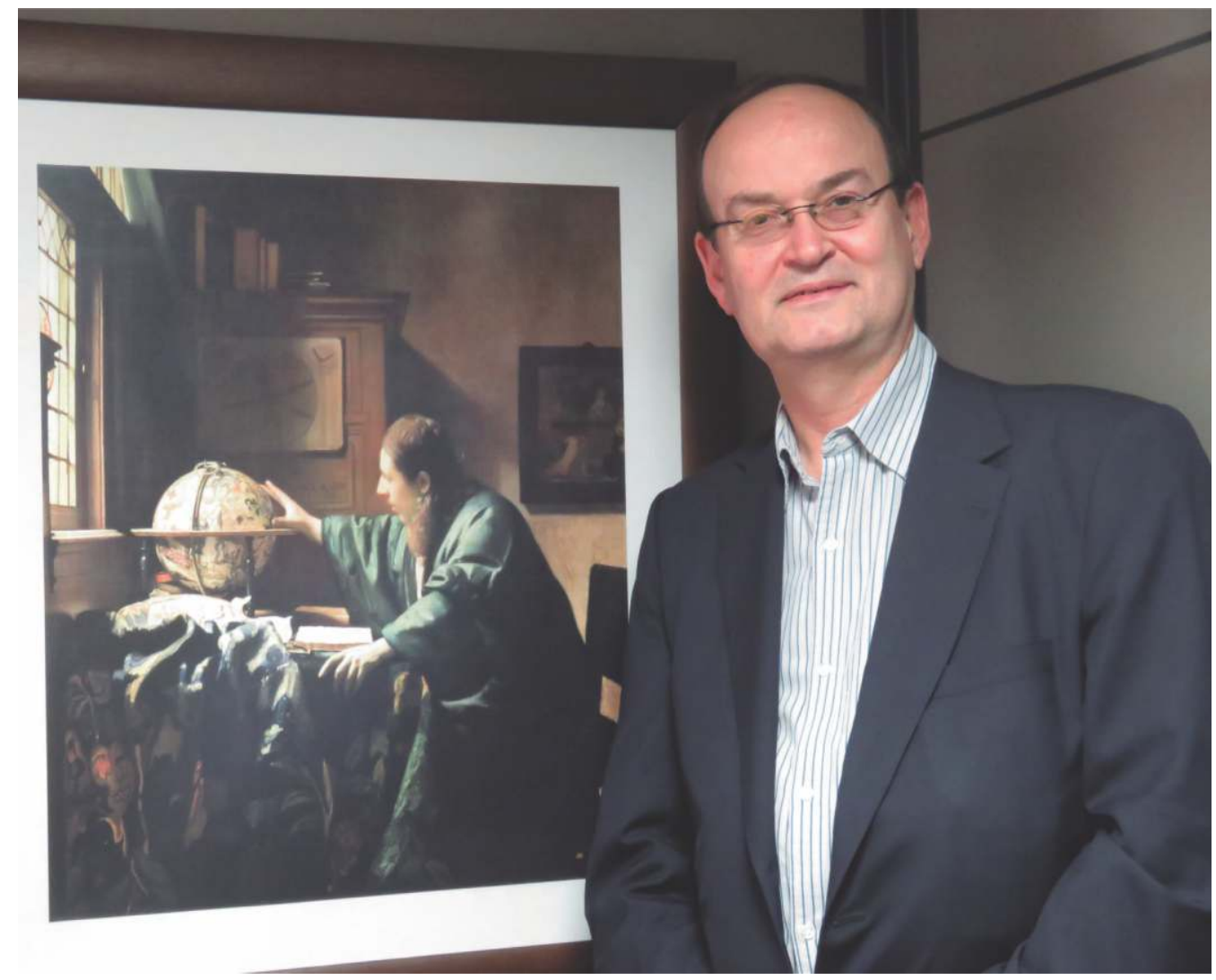

La ética ambiental, por su parte, cuando las tecnologías ponen en riesgo, perjudican o hacen un enorme daño al medio ambiente. La ética sobre la sexualidad aparece en el momento en que ésta se presenta como un problema en la vida humana, que siempre surge de formas diferentes. En resumen, la ética es transformada porque los nuevos problemas que rodean al ser humano, algunos de ellos cambiantes, demandan nuevas respuestas éticas.

MD: ¿Hay entonces comportamientos no éticos que pueden dejar de serlo debido a los cambios de las circunstancias?

PVD: Sí. Por ejemplo, en el siglo XVIII, cuando empezaron a desarrollarse las vacunas, en términos éticos no era claro si era lícito usarlas, toda vez que implicaban un riesgo para las personas y algunos optaron por su aplicación, frente a otros que se negaban a hacerlo. Hoy en día nadie le concede importancia moral a eso. En lo relacionado con la economía, el tema del préstamo a interés es interesante. Prestar dinero, según lo registran algunos textos del Antiguo Testamento y en la tradición cristiana, se 
consideraba un pecado, pero hoy la iglesia tiene bancos. ¿Por qué? Porque los problemas éticos surgen como los seres vivos, en el marco de un proceso que comienza y termina. En muchos sentidos, la ética es afectada por la tecnología y da lugar a replantear algunas problemáticas que antes no existían, eso es normal y siempre ha sido así.

\section{MD: En otras palabras, ¿las tecno- logías suponen un nuevo problema} ético?

PVD: Sí. Hoy en día las tecnologías nos permiten mejorar muchos aspectos de la vida. Uno, muy importante es el de la información, a la cual se puede acceder desbordando las posibilidades anteriores para obtenerla, compararla, entenderla y mirarla en un contexto global. En el Big Data, los algoritmos ayudan a predecir el comportamiento y las realidades humanas de una forma diferente y mucho más completa que implica nuevos desafíos éticos. La ética no está en las herramientas, sino en las personas que las utilizan, en el ser humano con todos sus problemas, sus ambigüedades, un ser que es egoísta, que quiere adquirir cosas que no tiene y que está dispuesto a hacer cosas que no están bien hechas para adquirirlas. En la era digital estas nuevas tecnologías pueden ser bien o mal utilizadas. El acceso a la información, por ejemplo, puede darse bajo pretensiones salidas del tono ético de la humanidad para hacer el mal, para perturbar los mercados. Cuando, por ejemplo, una compañía dispone de información producto del análisis, eso implica secreto y confidencialidad y ahí estamos hablando del tema ético de la fidelidad a una institución que te ha entregado una información. Hay muchos funcionarios y entidades públicas y privadas con información privilegiada que no cualquiera puede tener. El uso de esa información en el marco de lo pactado es un asunto ético que nunca será sustituido, porque las máquinas, aunque puedan ser programadas para tomar decisiones, nunca tendrán criterios éticos originales. La variedad de tareas que éstas realizan está transformando a la sociedad.

\section{MD: De ahí la importancia de de- batir sobre estos asuntos.}

PVD: Claro que sí. Ahí yo le añadiría algo que a lo mejor tiene que ver con la segunda pregunta y es que todavía no sabemos -no sé si ustedes los ingenieros de sistemas lo tienen claro-, pero yo no sé hacía donde van tales tecnologías y cuál es su alcance. En la película 2001, Odisea del Espacio, por ejemplo, la nave parece que se revela contra los seres humanos, y decide actuar con su voluntad.

MD: Emmanuel Lévinas, habla de la responsabilidad por el otro y dice 
"Basta con mirar al otro a los ojos para saber que se tiene una responsabilidad por esa persona". ¿Cómo se puede tratar este concepto cuando el otro es una multitud como se ve en las opiniones publicadas en las redes sociales?

sea, una comunicación de uno a muchos.

PVD: Se podría pensar que la tecnología tiende a hacer desaparecer el rostro del otro en algunos aspectos, como si el otro no existiera y sólo fuera un número o un número IP; pero el rostro del otro, tal y como Lévinas lo entiende, es imaginado por uno; no sólo el rostro gráfico con ojos y con sonrisa, sino de pronto con lágrimas, con angustias, tristezas o alegrías. Yo creo que es una manera de representar lo que dice Lévinas, y creo que él fue mucho más allá, pues el rostro del otro no es una cuestión de imaginación gráfica, sino de la conciencia de que no estamos solos, que hay otros 'yos' y que ese otro yo puede estar también detrás de la pantalla de un computador. Podría ser un anónimo que no conozco, quien, a través de Internet, de chats o de la tecnología en general, quiere buscar comunicación con otras personas y se esconde con pseudónimos, con perfiles que no corresponden a la realidad, ocultando el rostro, y hasta la edad y el género para manipular y utilizar a otros. Hoy en día, por ejemplo, hace mella el tema del abuso en niños. ¿Por qué? Porque obedece a intereses que persiguen esas personas. Estos asuntos suponen una tecnología nueva, pero, en el fondo, la desaparición del rostro del otro también tiene que ver con una disposición del ser humano para negar algo que él sabe que no puede negar. A pesar de que la tecnología permita ocultar el rostro, despersonalizarlo, deshumanizarlo, en el fondo la ética sigue siendo un asunto de relación entre personas mediada por la tecnología. $Y$ yo me cuestiono si la tecnología digital logra ocultar totalmente el rostro del otro.

¿Por qué digo que la posición de Lévinas podría ser muy fuerte, interpretándola? Porque no es una cuestión gráfica de identidad, sino un recordatorio o una presencia más que un recordatorio, que me cuestiona y me interpela. La desaparición del rostro del otro sería la desaparición de la dimensión humana de la vida que implicaría que no nos estamos reconociendo como humanos, así nos ocultemos detrás de un perfil de Facebook o de Instagram. Detrás de ese perfil falso hay un rostro verdadero, un rostro auténtico, así yo no lo conozca, está ahí. El problema es que se utiliza esa capacidad de ocultamiento para hacer mal. Entonces, insisto, el tema no es la tecnología, es el corazón humano si queremos ponerlo en esos términos. Por otro 
lado, la tecnología y la sociedad masificada, la sociedad del afán y del poco tiempo, de lo instantáneo, del cambio súbito y apresurado puede debilitar esa presencia.

En el caso de los rostros sufrientes, de los pobres y de los mendigos nos acostumbramos a ello y entonces ya no nos dicen nada, porque se vuelve algo cotidiano, que ya no dice nada nuevo. Hoy en día también las tecnologías permiten eso, pero también son una posibilidad para descubrir el rostro del otro. Así como pueden ocultarlo, pueden revelarlo, pueden mostrarlo y entonces volvemos a lo mismo, no es la tecnología la culpable. Son las personas, las intenciones y las disposiciones humanas, las capacidades humanas, la bondad humana o la maldad humana, las que hacen que la tecnología se vuelva perversa o sea una herramienta maravillosa. Hay gente que a través de las tecnologías ha desarrollado nuevas formas de relación con personas que no conocen; de solidaridad, de contacto, de dar a conocer la situación que viven. Los venezolanos, a quienes tenemos muy cerquita, son un ejemplo; otro está en la China o en otros países lejanos como el África, visibles a través de la tecnología,

\section{MD: Entonces, nos dice algo el libro del profesor Luigi Zoja sobre la muerte del prójimo?}

PVD: Sí. El libro de Zoja La muerte del prójimo, dice algo así como que lo que conduce a la muerte del prójimo es la muerte de Dios. Es decir, cuando Dios desaparece de la vida humana -la muerte de Dios proclamada por Nietzsche, desaparece también el rostro del otro como prójimo, porque la estructura cristiana dice: "amarás a Dios sobre todas las cosas y al prójimo como a ti mismo". Al desaparecer Dios, desaparece el prójimo, desaparece el prójimo como el otro tú mismo, y seremos incapaces de reconocernos en el rostro del otro.

MD: En Google hay cinco mil millones de consultas al día. Esos datos son utilizados por los algoritmos para pronosticar eventos debido a las múltiples evidencias de los hechos, lo cual genera patrones de comportamiento. ¿Sobre ese tema de pronosticar a través de los datos, tiene algún comentario?

PVD: Sí. Eso lo hemos visto también en la opinión pública. A propósito, yo recuerdo en la elección del presidente Trump en los Estados Unidos, cómo se utilizó el Big Data para influir en la opinión política de las personas, interpretando sus sentimientos, mediante mensajes dirigidos a orientar el criterio político en un sentido o en otro, conociendo además la manera de pensar de la gente. Eso evidentemente es un problema ético y es un asunto que las nuevas tecnologías plan- 
tean, porque antes no existía lo que se dice de la masificación de la mentira como herramienta. Sin embargo, la publicidad siempre ha estado orientada de acuerdo con los intereses de los consumidores y los publicistas siempre hacen una investigación antes para saber qué es lo que la gente espera, las expectativas, los deseos, los sueños, para saber cómo presentar un producto, ya sea una gaseosa, un cigarrillo o un automóvil y cómo impresionar. Esa problemática siempre ha existido y yo creo que a mí no me asusta que el Big Data pueda predecir el comportamiento del ser humano hasta cierto punto, y ese "hasta cierto punto" es muy importante porque el comportamiento humano, por más que sea manipulable, tiene límites. Yo soy de los que todavía cree en la libertad humana y a pesar del flujo que el Big Data pueda tener sobre mi comportamiento, sé que puedo mantener una cierta y relativa libertad al tomar mis propias decisiones.

Creo que no todo en la vida puede ser igualmente predecible. Me preocupa que la vida humana se vaya convirtiendo, por la presencia de estas tecnologías, en la negación de esas instancias que nos permiten tomar distancia, negar ciertos contenidos que se me presentan. Cada rato descubro que si empiezo a oír una emisora y empiezan a decir bobadas, la apago. In- clusive, llega un momento en que yo puedo apagar el celular y no quiero entrar a las redes sociales y voy a sacarle una hora a la meditación, para no ponerlo en términos de oración o religión.

Se trata de mirar para adentro y discernir mis más profundas ideas y sentimientos. Eso es lo que hacen los monjes budistas, se van entrando dentro de sí mismos y van descubriendo en el silencio, sus voces interiores. Me parece que eso hay que mantenerlo para poder manejar esas influencias del Big Data. Sin vida interior la tecnología puede hacer mucho daño.

La cultura digital de hoy, llamémosla así, va más allá de la tecnología digital, y cada vez son más reducidas esas posibilidades de control y la gente cree que está siendo libre cuando en realidad otros están influyéndolo en un sentido u otro. Eso exige que en el mundo haya espacios alternativos donde decidamos apagar el celular y nos miremos a la cara para conversar, evitando estar pendientes de si nos están llamando o si me están enviando un mensaje del banco o no; poder crear un momento en que están las dos personas frente a frente; eso se da a nivel de la pareja, de los amigos, de la familia y a nivel académico. Cuando yo estoy en clase veo que a algún estudiante le suena el celular, aunque lo tenga en modo de si- 
lencio. A esos estudiantes les invaden la clase y posiblemente otros momentos de la vida.

\section{MD: El tema sobre las redes socia-} les es otro asunto que afecta a la sociedad y que a pesar de que la gente habla de cerrarlas o controlarlas, de todas maneras, es una muestra de cómo es la sociedad. ¿Cómo ve usted esta nueva forma de vida?

PVD: Estamos aprendiendo, no digo que somos niños, pero sí estamos como bebés con el tema de las redes sociales; aprendiendo apenas a mamar de la teta de la mamá, aprendiendo a dar los primeros pasos al conocimiento y a la exploración de qué es eso que se me presenta. Pareciera que sabemos muy bien en qué consisten y creo que en eso hay una gran mentira. Las redes sociales todavía están tan jovencitas, tan niñas, tan bebés que no sabemos qué va a pasar con ellas como cuando ves un bebé y te preguntas: ¿cómo va a ser?, ¿va a ser alto, bajito, gordo, flaco, inteligente o no tanto?, ¿buen deportista o mal deportista? No tenemos ni idea.

Creo que con las redes sociales pasa algo similar y eso no significa que sean un problema y que no sean una posibilidad. No deben demonizarse o exaltarlas ilimitadamente, pues esto es la nueva realidad, esto es el mundo. ¿Por qué?
Porque lo que vemos es que las redes sociales son utilizadas muy bien en algunos casos y muy mal en otros. Es decir, que las cosas en sí mismas no son ni buenas ni malas, depende del uso que se les dé.

Me parece que en ese sentido es necesario reelaborar un sentido de democracia en el mundo digital. En muchos ámbitos se dice que la democracia en el mundo está en crisis. En la economía, por ejemplo, los monopolios no son democráticos, pero, infortunadamente, las cosas se hacen bajo el amparo de la democracia, utilizando sus posibilidades, un poco en contra de la democracia misma. Yo creo que eso es verdad y me parece que debemos estar muy atentos a cómo, en el mundo de la política, las redes sociales no pueden ser utilizadas en contra de la democracia.

Creo que hay que hablar de un freno, de un cierto límite. Me inspiro mucho en la idea de Kant, en el sentido de que la libertad, si no se limita, se destruye a sí misma.

En la libertad, lo dice Kant, somos los legisladores morales quienes elaboramos la ley moral y esa ley moral nos limita a nosotros mismos. Somos los autores de la ley. Si eso no ocurre así, la libertad acaba estrellándose contra la pared y se destruye. ¿Quién pone esos límites? Ahí está el problema. 
MD: ¿Son las leyes necesariamente las únicas que deberían ponerlos límites?

PVD: No. Pero tiene que existir una instancia objetiva, pues las redes sociales no pueden utilizarse para la criminalidad, tiene que haber un control y una cuenta en Twitter no se puede utilizar para calumniar o para engañar. Si eso sucede la pueden cancelar, se puede denunciar.

Ya intuimos un poco que las redes no pueden ser de tal modo abiertas, que pueden ser utilizadas para el bien, pero que no da lo mismo utilizarlas para el mal, para el crimen, pues eso va en contra del bien común o en contra de la vida humana. Es lo mismo que sucede con la prensa en la que todos estamos a favor de su libertad, pero cuando se utiliza para calumniar, se debe tener el derecho de decir: -un momentico, me están calumniando o me están perjudicando. Es lo mínimo para poder defenderme o si no, eso se vuelve una guerra, una promoción ingenua de violencia. Si yo no puedo quejarme, lo que voy a hacer es violencia contra ti. $Y$ entonces volvemos al mundo en donde la ley no tiene cabida y es la ley del más fuerte.

Insisto en que por más era digital, el tema ético tiene que ver con el ser humano, de la libertad humana, del hombre virtuoso como diría Aristó- teles. El hombre virtuoso es el hombre que hace las cosas bien hechas. Entonces cuando tiene conflictos sabe resolverlos bien y cuando tiene problemas sabe hacerlo más o menos. Me da mucho miedo cuando se plantea el tema de las tecnologías y creemos que es la solución a ese tipo de problemas. Nada reemplaza aquella frase tremenda de San Agustín: "si amas haz lo que quieras. No necesitas leyes".

MD: Sobre el comportamiento de los carros autónomos apareció un sitio llamado "la máquina moral", en el que se pregunta cuál debe ser la decisión a tomar cuando estén comprometidas personas externas versus las que van en el carro. La pregunta que hacen es ia quién debe salvar? ¿Qué piensa usted sobre este tipo de algoritmia?

PVD: Desde mi perspectiva, los algoritmos son una herramienta, pero la herramienta nunca reemplaza la intención. Una herramienta siempre está en las manos de alguien, el algoritmo no es la mano. Parece que se nos dice que el algoritmo toma la decisión, pero no lo creo. Sí puede haber un consenso ético sobre lo que la mayoría de las personas o un conjunto de seres humanos piensan alrededor de lo que debería hacer la máquina. Ese es un juicio descriptivo sobre un universo de personas encuestadas, de un grupo que opina sobre una decisión. Pero la ética no se confronta 
solamente con hechos, sino con lo que debe ocurrir. La posibilidad misma de que tú te preguntes si eso es correcto o no, indica que ya hay una posibilidad por fuera del algoritmo.

Ningún algoritmo -en mi conceptoanula la libertad humana para tomar distancia frente a él. Puede que todas las personas en las mismas circunstancias asesinen a otro, mientan o acepten un soborno. Puede que todos los policías -eso lo dice Kant muy claramenteo todas las personas mientan, pero el algoritmo sobre el comportamiento de la gente con la mentira no legitima la mentira. Los elaboradores del algoritmo a lo mejor piensan que sí; si todo el mundo miente no tiene sentido decir que no se debe mentir. $Y$ yo pienso como Kant, que no se debe mentir, así todo el mundo mienta.

Ese es un argumento muy fuerte desde la filosofía, o digamos desde la conciencia o del individuo de Kant, y eso él lo dice casi que textualmente: aun cuando todo el mundo mienta, yo siempre pensaré que no debo mentir y nunca el comportamiento de otros va a validar algo que yo considero que no es lo correcto. Este criterio pondría un límite al algoritmo. Hay decisiones en las que uno se pregunta ¿el ser humano es capaz de emitir juicios morales sobre las soluciones de los algoritmos? O ¿no? El ser humano sí tiene la capacidad de criticar una decisión algorítmica y modificarla. La gente, por ejemplo, no propondría salvar el carro por encima de una persona.

En mi opinión, todo esto debe estar en la formación de los ingenieros, los economistas, los médicos, en todos los profesionales. Desde hace mucho tiempo la universidad se pregunta cosas como esas. Lo que habría que hacer es enfatizar en una sensibilización muy grande sobre las situaciones humanas en las que el contacto directo con las personas no puede ser soslayado o evitado a través de la tecnología. La educación tiene que sensibilizar a las personas por la situación que viven los otros, los de otras religiones, de otra orientación sexual, de otras culturas, de otras razas, de otras procedencias y no dar por hecho que todos los seres humanos reaccionamos y vivimos lo mismo con los mismos fenómenos. Eso es muy importante en el mundo de hoy.

Por ejemplo, en el tema de la diversidad sexual y los derechos de los homosexuales, el matrimonio gay, la adopción de niños por pareja de homosexuales, entre otros ejemplos, la sociedad tiende a estandarizar y a pensar que son concebidos de la forma igual para todos. $Y$ no es así. A eso me refiero cuando 
planteo la necesidad de sensibilizar la forma como las personas perciben el mundo. Eso es muy complicado porque no significa ocultar información, no significa modificar la información, no significa una posición paternalista o qué deben ver los demás y qué no. Yo no sé si los programadores o los economistas piensan que una decisión sobre el sistema económico tiene los mismos efectos en Nueva York, en Colombia o en la India. La cultura humana es muy compleja y no permite asumir que todo el mundo piense igual. En mi opinión ese es un tema en el que el mundo se ha vuelto muy duro e intransigente. Lo que está en las redes es lo que nos une, pero lo que está en la red lo dice alguien, no se hizo solo, luego alguien nos está trasmitiendo su visión desde su pensamiento del hecho.

En estos temas recurro más a Kant que a Hegel. El acceso a esa posibilidad de formar en la sensibilidad y en la comprensión del otro, se puede lograr de muy diferentes formas. Hegel pensaba, por ejemplo, que la verdad en un sentido absoluto sólo se logra a través de la religión, del arte o de la filosofía. Quien comprende el mundo realmente, es quién está en capacidad de decir qué comprende el mundo.

Un ejemplo que nos ayuda a entender esto es la visión que hay en la pintura de Van Gogh sobre el ser humano. ¿Será que uno pudiera pensar que Van Gogh comprendió al ser humano y al mundo mejor que un científico? O creemos que ¿el físico o el ingeniero, el diseñador de procesadores y de Big Data y de algoritmos es el que realmente comprende el mundo? ¿Qué tal si el que mejor comprende el mundo es un monje budista que está en Nepal? En el mundo en que vivimos, la mayoría de la gente piensa que no. El ingeniero es el que mejor comprende el mundo... Este es supuesto muy delicado, pues si uno le pregunta a los del Wall Street, nos responden que quienes comprenden mejor el mundo son los economistas. Pero ¿Qué es comprender el mundo? ¿Comprender las relaciones? ¿Comprender los algoritmos? ¿Comprender la materia? Le puede preguntar a un físico o a un químico y tal vez digan que el que mejor comprende el mundo es el que mejor comprende la materia. ¿Y qué pasa con la visión de un artista?

Es muy importante que los economistas lean a Shakespeare, como sugiere Nussbaum. Y uno dice, pero ¿por qué es importante que los economistas lean a Shakespeare? Que los economistas de Harvard lean a Shakespeare es importante porque van a entender que el ser humano es mucho más que lo que ellos creen que es el ser humano. 
¿Podemos sencillamente suponer que el monje budista que está encerrado meditando en Nepal es un pobre diablo que no entiende nada del mundo? Sin tener celular ¿va a entender el mundo? ¿No será que de pronto él lo está entendiendo mejor? Y que vean a ese 'pobre diablo' que está en el río Ganges en la India vestido así con trapos lleno de pinturas, y que lo vean mejor con cierta empatía, con la capacidad de sentir lo que él siente y pensar lo que él piensa ¿así sea muy difícil? Y que ¿a lo mejor ese ser humano no está equivocado, no está loco, no es delirante premoderno?

El otro día con un amigo teníamos un evento en Cartagena y él no usa celular. Yo estaba desesperado porque el amigo no tenía celular ni donde llamarlo. ¿El problema es mío, es de él o del mundo? ¿De quién es? El mundo nuestro está funcionando así. Eso nos lleva a pensar que el que no tiene celular, está fregado hoy. ¿Y eso está bien?

En el caso del Gurú de la India, se le considera que está desubicado en el mundo, que no está en la realidad.

Algo no funciona ahí bien. Y por eso digo que no renunciemos a la tecnología, pero los que la manejan sí deberían ser más sensibles a la diversidad de las situaciones humanas.

\footnotetext{
Manuel Dávila Sguerra. Director de Ciencias y tecnologías para la vida del Parque científico de innovación social de Uniminuto, Ex decano de la Facultad de Ingeniería de Uniminuto. Ingeniero de Sistemas de la Universidad de Los Andes, Maestría Cum Laude en Filosofía Universidad Javeriana, Columnista de Computerworld, eltiempo.com sobre Linux y el software libre. Tiene 160 artículos publicados y cuatro libros sobre informática. Autor de la plataforma e-Genesis- El Generador de sistemas para la generación automática de software, mención especial en el Premio Colombiano de Informática 2006, miembro fundador de varias asociaciones: Asociación de industriales del software Indusoft, hoy Ilamada Fedesoft; Asociación Colombiana de Ingenieros de Sistemas-ACIS; gestor y expresidente de la red de Programa de Ingeniería de sistemas, REDIS.
} 